Physical Education Teachers Association of Turkey Türkiye Beden Eğitimi Öğretmenleri Derneği
Journal of Physical Education and Sports Studies (JPESS) Beden Eğitimi ve Spor Araștırmaları Dergisi (BESAD)

e-ISSN 2602-3644

Cilt 10, Sayı 1 (2018) Mart

URL http://www.besad.org

\title{
A Need Analyses For Pilates Educational Training
}

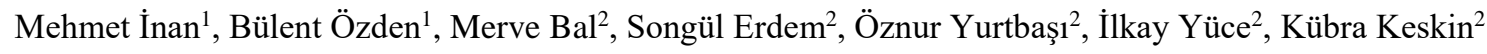

\footnotetext{
${ }^{1}$ Marmara University, Atatürk Faculty of Education, minan@marmara.edu.tr

${ }^{2}$ Marmara University, Institute of Educational Sciences, mrvbal@ hotmail.com
}

Received: 17.01 .2018

Accepted: 20.03.2018

Online Published: 22.03.2018

doi: $10.30655 /$ besad.2018.5

\begin{abstract}
The aim of this study is to specify the needs of Pilates instructors' educational needs. In this study which was designed as a case study, focus interviews were conducted with 26 participants whose 3 of them managers, 9 of them instructors and 14 of them members. Content analysis method was used in the analysis of qualitative data that was obtained from the interviews. In the interviews with participants, findings in five dimensions were obtained in Pilates educational training as basic knowledge and skills, communication skills, practice knowledge and skills, environment regulation knowledge and skills and measurement knowledge and skills. Participants in the basic knowledge and skills dimension indicated that Pilates instructors need to obtain basic sports, health and anatomic knowledge. In the practice knowledge and skills dimension, according to the participants, Pilates trainers should have knowledge and skills such as creating group levels, making corrections and giving feedback. According to participants, Pilates instructors should also be able to use communication skills effectively. In the Pilates training, especially the spaciousness of the environment, the presence of mirrors and music was indicated essential by the participants. For the measurement dimension, participants indicated that Pilates trainers should be able to make body measurements.
\end{abstract}

Key words: Pilates, Education of Instructor, Need Analysis

\section{Pilates Eğitici Eğitimine Yönelik Bir İhtiyaç Analizi Çalışması}

\section{$\ddot{\mathbf{O} z}$}

Bu araştırmanın amacı pilates eğiticilerinin eğitim ihtiyaçlarını belirlemektir. Durum çalışması modeline göre desenlenen araştırmada 3 yönetici, 9 eğitmen ve 14 üyeden olmak üzere toplam 26 katılımcı ile odak görüşmeler yapılmuştır. Görüşmelerle elde edilen nitel verilerin analizinde içerik analizi yöntemi kullanılmıştır. Katılımcılar ile yapılan görüşmelerle pilates eğitici eğitiminde temel alan bilgi ve becerileri, iletişim becerileri, uygulama bilgi ve becerileri, ortam düzenleme bilgi ve becerileri ve ölçme bilgi ve becerileri olmak üzere beş boyutta bulgular elde edilmiştir. Temel alan bilgi ve becerileri boyutunda katılımcılar pilates eğiticilerinin temel spor, sağllk ve anatomi bilgisi edinmeleri gerektiğini belirtmişlerdir. Uygulama sürecinde ise katılımcllara göre pilates eğiticileri seviye grupları oluşturma, düzeltmeler yapma ve geribildirimler verme gibi bilgi ve becerilere sahip olmalıdır. Katılımcılara göre pilates eğiticileri iletişim becerilerini etkili bir şekilde kullanabilmelidir. Pilates eğitiminde özellikle ortamın ferah olması, aynaların ve müziğin bulunması katılımcılar tarafindan belirtilmiştir. Ölçme boyutu içinse katılımcılar pilates eğiticilerinin vücut ölçümleri yapabilmeleri gerektiğini belirtmişlerdir.

Anahtar Kelimeler: Pilates, Eğitici Eğitimi, İhtiyaç Analizi 


\section{Giriş}

Günümüzde yaygın bir şekilde yapılan Pilates egzersizleri, özellikle konsantrasyon gerektiren hareketler ile vücut postürünü geliştirmek ve sağlıklı bir vücuda sahip olmak için uygulanmaktadır (Selby, 2002). Kasların eğitimini hedef alan Pilates yönteminde egzersizler çok hafif ama aynı derecede dikkat gerektiren bir yapıda başlar. Kişinin, bu küçük hareketleri gövdesinin stabilizasyonunu sağlayarak başardığı durumlarda, daha zor aktivitelere geçilir. Böylece vücut farkındalığı gelişir. Kişi, bilinçli olarak aklı ile bedenini kontrol etmeyi öğrenir. $\mathrm{Bu}$ öğrenme hayatının geneline aktarılır. Pilates egzersizlerini sunacak olan eğitmenlerin pek çok becerilere sahip olması ve bu alanda uzman kişiler olmaları oldukça önemlidir.

Pilates egzersizleri sırasında kişi sürekli bir eğitim altındadır. Zihinsel ve fiziksel iyi olma durumunu geliştirir, mat üzerinde veya herhangi bir ekipmanla kontrollü olarak yapılan hareketler omurganın stabilizasyonunu sağlayarak, esnekliği, koordinasyonu, dayanıklılığı geliştirir, kasların şişmesini engelleyip kuvvetlendirerek, vücudun güçlenmesine yol açar. Pilates egzersizlerinin insan yaşamı üzerindeki etkilerini inceleyen çeşitli araştırmalar yapılmıştır. Esneklik performansını geliştirdiği, beden kompozisyonu üzerine olumlu etkilerin ortaya konulduğu çalışmalar (Jago, Jonker, Missaghian ve Baranowski, 2006; Rogers ve Gibson, 2009; García Pastor ve Aznar Lain, 2011; Singh ve Singh, 2014) dışında, karın bölgesi ve lumbo pelvik stabilizesini (Bernardo, 2007), abdominal kuvveti merkez postürün yanı sıra üst omurga postürünün stabilizasyonunu (Emery, Serres, McMillan ve Cote, 2010), nöromotor fitnes, özellikle dengeyi (Appell, Perez, Nascimento ve Coriolano, 2012; Cancela, de Oliveira ve Rodríguez-Fuentes, 2014) sırt kasları ve hamstring kaslarının esnekliğini (Mamashli, Mahdavinejad ve Gholamali, 2014), genel sağlık kondisyonunu (Pourvaghar, Bahram, Sharif ve Sayyah, 2014), core kas performanslarını (Abramaviciute, Zaicenkoviene ve Sujeta, 2013) olumlu yönde etkilediğini ortaya koyan çalışmalar da mevcuttur. Bunun aksine Aladro Gonzalvo, Machado-Diaz, Moncada-Jimenez, Hernandez-Elizondo ve ArayaVargas (2012) yaptıkları tarama çalışmasında pilates egzersizlerinin vücut kompozisyonu üzerine etkisini belirten kesin deneysel bilgilerin yeterli olmadıklarını savunurlarken Tsai, Liou, Kao, Wang ve Huang (2013); Da Cruz ve diğerleri (2014) de herhangi bir etkiden söz etmemektedirler.

Pilates egzersizleri amacına uygun bir şekilde uygulandığı takdirde önemli kazanımları olan bir spor dalıdır. Pilates eğitmenlerinin pilates egzersizlerini amacına uygun bir şekilde sunabilmelerinde federasyondan aldıkları belgeler ihtiyacı karşılamakta mıdır? Daha donanımlı bir eğitim verilmeli midir? Eğitmenler alınan eğitimden yeterli donanıma bezenmiş bir şekilde 
uzman olmakta mıdırlar? İnsan sağlı̆̆ı üzerindeki etkileri bakımından Türkiye'de son yıllarda çok rağbet gören pilates egzersizleri, hedef kitleye bu eğitimi verecek olan kişilerin aldığ1 eğitimlerin niteliğinin incelenmesine gerek duyulmuştur. $\mathrm{Bu}$ amaç çerçevesinde eğitmenlerin eğitim gereksinimleri "ihtiyaç belirleme" çalışması olarak ele alınmıştır.

\section{Yöntem}

Araştırma durum çalışması modeline göre desenlenmiştir. Durum çalışması modelinde, bir duruma ilişkin etkenler (ortam, bireyler, olaylar ve süreçler) bütüncül bir yaklaşımla araştırılır. $\mathrm{Bu}$ etkenlerin bu durumu nasıl etkiledikleri ve ilgili durumdan nasıl etkilendikleri tespit edilmeye çalışılır (Yıldırım ve Şimşek, 2016). Bu araştırmada da pilates eğitici eğitimine yönelik ihtiyaç analizi yapmak amaciyla pilates eğitimi sürecinin etkenleri olarak eğitmen, yönetici ve pilates kursuna devam eden üyeler ele alınmıştır. Bu etkenlerden pilates eğitimi sürecinde nelerin etkili olduğu ve bunlardan nasıl etkilendiklerine dair bulgular elde edilmeye çalışılmıştır. $\mathrm{Bu}$ bulgulardan yola çıkarak araştırma durumu olarak ele alınan pilates eğiticilerinin eğitimine yönelik ihtiyaç tespitleri yapılmıştır.

Çalışmada 3 yönetici, 9 eğitmen ve 14 üye olmak üzere toplam 26 katılımcı amaçlı örnekleme yöntemlerinden maksimum çeşitlilik örneklemesine göre seçilmiştir. Maksimum çeşitlilik örneklemesinde amaç probleme taraf olabilecek bireylerin çeşitliliğini maksimum derecede yansıtabilmektir (Yıldırım ve Şimşek, 2016). Pilates eğitmenlerinin eğitim ihtiyaçlarını belirlemek üzere katılımcılar ile görüşmeler yapılmıştır. Görüşmelerde kullanılmak üzere araştırmacılar tarafından hazırlanmış ve 9 sorudan oluşan bir yarı yapılandırılmış görüşme formu kullanılmıştır. Formdaki sorulardan bazıları şu şekildedir: "Sizce bir pilates eğitmeninin özellikleri neler olmalıdır? Yaş, seviye ve özel gruplara göre ayrım yapılıyor mu? Sizce grupların oluşturulması nasıl olmalıdır? Sizce ideal bir pilates çalışması ne kadar süre ile yapılmalıdır?, vb.”.

Görüşmelerle elde edilen nitel verilerin analizinde içerik analizi yöntemi kullanılmıştır. İçerik analizinin amacı, toplanan verileri açıklayabilecek kavramları ve ilişkileri belirlemektir. $\mathrm{Bu}$ amaçla veriler önce kavramsallaştırılır, belirlenen kavramlara göre düzenlemeler yapılır ve veriyi açıklayan temalar oluşturulur (Yıldırım ve Şimşek, 2016). Verilerin analizi sürecinde öncelikle katılımcılarla yapılan görüşmeler sonucunda elde edilen veriler okunmuş ve kodlar oluşturulmuştur. Daha sonra bu kodlardan yola çıkarak temalar oluşturulmuştur. Temalar oluşturulduktan sonra veriler temalar dikkate alınarak yeniden okunmuş ve kodlama süreci gerçekleştirilmiştir. Kodlayıcılar arası güvenirlik [uzlaşılan kodlar/(uzlaşılan + uzlaşılmayan 
kodlar)]x 100 formülü (Miles ve Huberman, 1994) ile hesaplanmış ve \% 88 olarak belirlenmiştir Miles ve Huberman'a (1994) göre kodlayıcılar arası güvenirlik \%80’den büyük ve mümkün olduğunca \%90’a yakın olmalıdır.

\section{Bulgular}

Pilates eğitmenleri, salon yöneticileri ve üyelerle yapılan görüşmeler sonucunda Pilates eğitmenlerinin eğitim ihtiyaçlarına yönelik bulgular "Temel alan, iletişim, uygulama, ortam hazırlama ve ölçme bilgi ve becerileri” olmak üzere beş alanda düzenlenmiştir. Pilates eğitmenleri, salon yöneticileri ve üyelere göre Pilates eğitmenlerinin temel alan bilgi ve becerilerine yönelik eğitim ihtiyaçları Tablo-1'de verilmiştir.

Tablo-1: Pilates Eğiticilerinin Temel Alan Bilgi ve Becerilerine İlişkin Eğitim İhtiyaçları

\begin{tabular}{clcccc}
\hline \multicolumn{1}{c}{ Tema } & \multicolumn{1}{c}{ Kodlar } & Ĕgitmen & Yönetici & Üye & Toplam \\
\hline & Alanında uzman olmalı & 5 & 2 & 7 & 14 \\
& Sağlik bilgisi & 3 & & 2 & 5 \\
& Farklı metot bilgisi & 4 & & & 4 \\
& Anatomi bilgisi & 1 & & 2 & 3 \\
Temel Alan Bilgi ve & Beslenme programı bilgisi & 1 & 1 & 1 & 3 \\
Becerileri & Kendi stilini oluşturma & 2 & & 2 \\
& Spor bilgisi & & 1 & & 1 \\
& Detoks bilgisi & 1 & & 1 & 1 \\
& Isıma bilgisi & & & & 34 \\
\hline
\end{tabular}

Katılımcıların çoğunluğuna göre pilates eğitmenlerinin alanında uzman olmaları gerekmektedir. Bunun yanında pilates eğitmenlerinden temel sağlık ve anatomi konularında bilgi sahibi olmaları beklenmektedir. Pilates eğitiminde hem farklı yöntemler kullanabilecek hem de kendi stillerini oluşturabilecek bilgi ve becerileri kazanmaları gerektiği vurgulanmıştır.

Pilates eğitmenleri, salon yöneticileri ve üyelere göre Pilates eğitmenlerinin iletişim becerilerine yönelik eğitim ihtiyaçları Tablo-2'de verilmiştir.

Tablo-2: Pilates Eğiticilerinin İletişim Becerilerine İlişkin Eğitim İhtiyaçları

\begin{tabular}{clcccc}
\hline Tema & \multicolumn{1}{c}{ Kodlar } & Eğitmen & Yönetici & Üye & Toplam \\
\hline & Güler yüzlü olabilme & 2 & 1 & 12 & 15 \\
& Diş görünüşe önem verme & 3 & 1 & 3 & 7 \\
& Etkili iletişim kurma & 1 & 2 & 3 & 6 \\
\multirow{3}{*}{ İletişim Becerileri } & Sabirlı olma & 3 & 2 & & 5 \\
& İlgili olabilme & & 1 & 3 & 4 \\
& Ses tonunu etkili kullanma & & & 2 & 2 \\
& Ayrim yapmama & & & 1 & 1 \\
& Kendine güvenme & 2 & & & 2 \\
& Toplam & 11 & 7 & 24 & 42 \\
\hline
\end{tabular}


Katılımcılar pilates eğitmenlerinin eğitimleri sırasında iletişim becerilerini doğru bir şekilde kullanmalarını gerektiğini vurgulamışlardır. Özellikle eğitmenlerin güler yüzlü olmaları, dış görünüşlerine önem vermeleri, etkili iletişim kurmaları, üyelere karşı sabırlı olmaları ve ilgi göstermeleri gerektiği belirtilmiştir. $\mathrm{Bu}$ yüzden pilates eğitmenlere yönelik düzenlenecek bir eğitim faaliyetinde iletişim becerilerinin geliştirilmesi önemli bir konu alanı olacağı söylenebilir.

Pilates eğitmenleri, salon yöneticileri ve üyelere göre Pilates eğitmenlerinin uygulama bilgi ve becerilerine yönelik eğitim ihtiyaçları Tablo-3'te verilmiştir.

Tablo-3: Pilates Eğiticilerinin Uygulama Bilgi ve Becerilerine İlişkin Eğitim İhtiyaçları

\begin{tabular}{clcccc}
\hline Tema & \multicolumn{1}{c}{ Kodlar } & Eğitmen & Yönetici & Üye & Toplam \\
\hline & Seviye grupları oluşturma & 6 & 3 & 12 & 21 \\
& Uygun süreyi ayarlayabilme & 9 & 3 & 12 & 24 \\
& Geribildirim ve düzeltme verme & & & 5 & 5 \\
& Nefes egzersizleri yapma & 4 & & & 4 \\
& Isınma egzersizleri yapma & 2 & & & 2 \\
Uygulama Bilgi ve & $\begin{array}{l}\text { Duruş bilgisi verme } \\
\text { Becerileri }\end{array}$ & 2 & & & 2 \\
& $\begin{array}{l}\text { Farkli vücut bölgelerini } \\
\text { çalıştırabilme }\end{array}$ & & & 2 & 2 \\
& Ortama hakim olabilme & 1 & & & 1 \\
& Programlı ve planlı olma & 1 & & & 1 \\
& Sözlü ve görsel sunu yapma & 1 & & & 1 \\
& Toplam & 26 & 6 & 31 & 63 \\
\hline
\end{tabular}

Katılımcılar pilates eğitmenlerinin uygulama sürecinde üyelerin yaşına veya seviyelerine göre gruplar oluşturabilmelerini ve uygun uygulama süresini belirleyebilme becerisine sahip olması gerektiğini belirtmişlerdir. Bunun yanında özellikle üyeler eğitmenlerin uygulama sürecinde kendilerine geribildirimlerin verilmesini ve düzeltmelerin yapılmasının önemini vurgulamışlardır. Bu açıdan eğitmenlerin geribildirim ve düzeltme konularında bilgi ve beceri kazanmalarının önemli olduğu söylenebilir. Ayrıca araştırmaya katılan pilates eğitmenleri uygulama sürecinde üyelere nefes ve 1sınma egzersizleri yaptırma ve onlara duruş bilgisi vermenin gerekli olduğunu ifa etmişlerdir. Bu nedenle pilates eğitmenlerine yönelik yapılacak bir eğitim etkinliğinde nefes ve ısınma egzersizleri ve duruş bilgisi konularında bilgi ve becerilerin kazandırılmasının önemli olduğu söylenebilir.

Pilates eğitmenleri, salon yöneticileri ve üyelere göre Pilates eğitmenlerinin ortam düzenleme bilgi ve becerilerine yönelik eğitim ihtiyaçları Tablo-4'te verilmiştir. 
Tablo-4: Pilates Eğiticilerinin Ortam Düzenleme Bilgi ve Becerilerine İlişkin Eğitim İhtiyaçları

\begin{tabular}{clcccc}
\hline Tema & \multicolumn{1}{c}{ Kodlar } & Ĕ̆itmen & Yönetici & Üye & Toplam \\
\hline \multirow{2}{*}{$\begin{array}{c}\text { Ortam düzenleme } \\
\text { bilgi ve becerileri }\end{array}$} & $\begin{array}{l}\text { Temizlik, malzemeleri sağlama } \\
\text { havalandırmaya dikkat etme }\end{array}$ & 6 & 3 & 6 & 15 \\
& $\begin{array}{l}\text { Müziği kullanma } \\
\text { Toplam }\end{array}$ & 1 & 2 & 8 & 18 \\
& 15 & 1 & 4 & 6 \\
\hline
\end{tabular}

Katılımcılar özellikle üyeler tarafından her ne kadar pilates eğitiminin yapıldığg ortamın aynalı olması, canlı renklere sahip olması, müziğin olması, iyi havalandırılması, temiz ve hijyenik olması gerektiğini vurgulansa da bunları gerçekleştirme sorumluluğunun eğitmende değil yöneticide olduğu bir gerçektir. Ancak yine de katılımcılar pilates eğitmenlerinin gerekli malzemelerin tam olması, temizlik, hijyen, yeterli havalandırma ve uygulama sürecinde müziği kullanma konularında farkındalık, alışkanlık ve tutum geliştirmeleri beklenmektedir.

Pilates eğitmenleri, salon yöneticileri ve üyelere göre Pilates eğitmenlerinin ölçme bilgi ve becerilerine yönelik eğitim ihtiyaçları Tablo-5'te verilmiştir.

Tablo-5: Pilates Eğiticilerinin Ölçme Bilgi ve Becerilerine İlişkin Eğitim İhtiyaçları

\begin{tabular}{clcccc}
\hline Tema & \multicolumn{1}{c}{ Kodlar } & Ĕ̆itmen & Yönetici & Üye & Toplam \\
\hline \multirow{2}{*}{ Ölçme Bilgi ve } & Vücut ölçümleri yapabilme & 7 & 3 & 12 & 22 \\
Becerileri & Gelişim notları tutabilme & 1 & & & 1 \\
& Karne oluşturabilme & 1 & & 1 & 12 \\
& Toplam & 9 & 3 & 12 \\
\hline
\end{tabular}

Katılımcıların çoğunluğu pilates eğitmenlerinin vücut ölçümleri yapabilme bilgi ve becerisine sahip olmaları gerektiğini belirtmişlerdir. Yağ, kas ve kilo ölçümlerinin yapılması özellikle üyeler tarafından vurgulanmıştır. Bu yüzden pilates eğitmenlerine yönelik düzenlenecek bir eğitim faaliyetinde vücut ölçümlerinin yapılmasına yönelik bilgi ve becerileri kazandırmanın gerekli olduğu söylenebilir. Bunun yanında eğitmenler üyelerin gelişim sürecine yönelik eğitmen tarafından notlar tutulabileceği ve bu notların gelişim karnesi şeklinde üye ile paylaşılabileceğini belirtmişlerdir. Üyelerin gelişimini takip etme ve gelişimlerini kayıt altına almaya yönelik eğitmenlere bilgi ve beceri kazandırılabilir.

\section{Tartışma ve Sonuç}

Pilates eğitici eğitimlerinin ihtiyaç duydukları eğitimi kendilerine sunmada hedeflerin belirlenmesi önemlidir. Hedef belirleyicilerin araştırma bulguları ve sonuçlarından elde edilen sonuçlara göre eğitim içeriklerini oluşturmaları daha gerçekçi eğitimlerin verilmesini sağlıyor olacaktır. Literatürde pilates ile ilgili vurgu çoğunlukla sağlık ve insan vücudu üzerindeki etkilerine yapılmaktadır (Rogers ve Gibson, 2009; García Pastor ve Aznar Lain, 2011; Singh ve 
Singh, 2014; Jago, Jonker, Missaghian ve Baranowski, 2006; Bernardo, 2007; Pourvaghar, Bahram, Sharif ve Sayyah, 2014). Bu araştırma bulgularında da katılımcıların vurgu yaptıkları temalar arasında "Temel Alan Bilgi ve Becerileri” gelmektedir. Ayrıca pilates eğitici eğitimlerinde teorik konulardan çok uygulamalara zaman ayrılması beklenilen bir durumdur.

Pilates eğitmenlerinin eğitim ihtiyaçlarına yönelik yaptığımız çalışma sonucunda 5 (beş) tema ortaya çıkmıştır.

1- Temel alan bilgi ve becerileri yönünden:

- Pilates eğitmenleri alanında uzman,

- Temel sağlık ve anatomi bilgilerini kazanmış,

- Eğitimlerde farklı yöntemlerini kullanabilen ve kendi stillerini oluşturabilen kişiler olmalıdır.

2- İletişim becerileri yönünden:

- Eğitmenler güler yüzlü,

- Diş görünüşlerine önem veren,

- Etkili iletişim kurabilen, sabırlı,

- İletişimin temel bilgi ve becerileriyle donanımlı olmalıdır.

3- Uygulama bilgi ve becerileri yönünden:

- Eğitmenlere hizmet içi eğitimlerde seviye gruplarının nasıl oluşturulması gerektiği bilgisi,

- Geribildirim ve düzeltme gibi eğitimin niteliğini oluşturan unsurlara nasıl yer verilmesi gerektiği bilgisi,

- Isınma ve nefes egzersizleri bilgisi,

- Duruş bilgi ve becerileri kazandırılmalıdır.

4- Ortam düzenleme bilgi ve becerileri yönünden:

- Pilates eğitimlerinde, pilates ortamlarında kullanılacak bilgilerin neler olduğu bilgisi ve gerekliliği,

- Temizlik, hijyen ve iklimlendirmenin nasıl olması gerektiği ile ilgili bilgi ve beceriler kazandırılmalıdır.

5- Ölçme bilgi ve becerileri:

- Pilates eğitimlerinde vücut ölçüm yöntemleri,

- Araçları, değerlendirme işlemleri ile ilgili bilgilere ve becerilere yönelik eğitimler alınmalidir. 
Araştırma sonuçları göz önünde bulundurulduğunda, pilates eğitici eğitimlerinin yetersiz kaldığı görülmektedir. Federasyon tarafından verilen eğitmenlik kurslarının bu sonuçlar bağlamında yeniden düzenlenmesi veya iyileştirilmesi önerilebilir. Yapılan araştırmada ve deneyimlerle de örtüşen doğrultuda biliyoruz ki pilates eğitici eğitimlerinde uygulama saatleri çok az olmakla birlikte, genellikle örnek model üzerinden eğitim verilmekte, herkesin her hareketi tek tek uygulama şansı olmamaktadır. İlgili federasyonun yapılacak olan eğitimlerde eğitici eğitimlerindeki uygulama sürelerini yeniden planlıyor olması, on bir günlük bir eğitim değil de, daha uzun, belki bir yıla yayılabilecek bir kurs planı yapmaları, böylece daha uzun süre uygulamaya zaman ayırmaları önerilebilir. Araştırmanın daha geniş örneklemli gruplarla yapılması gelecekteki pilates eğitimi eğitici ihtiyaçlarının karşılanmasına yeni katkılar sağlayabilir.

\section{Kaynaklar}

Abramaviciute, V., Zaicenkoviene, K., Sujeta, A. (2013). The influence of pilates exercise on women's anthrophometry indices, core muscle performance and heart rate changes during the session. Lithuanian Sports University, Education, Physical Training Sport, 2(89), 511 .

Aladro-Gonzalvo, A. R., Machado-Díaz, M., Moncada-Jiménez, J., Hernández-Elizondo, J., ArayaVargas, G. (2012). The effect of pilates exercises on body composition: A systematic review. Journal of Bodywork and Movement Therapies, 16(1), 109-114.

Appell, I. P. C., Perez, V. R., Nascimento, M. D. M., Coriolano, H. J. A. (2012). The pilates method to improve body balance in the elderly. Archives of Exercise in Health and Disease, 3(3), 188- 193.

Bernardo, L.M. (2007). The effectiveness of pilates training in healthy adults: An appraisal of the research literature. Journal of Body Work and Movement Therapies, 11, 106-10.

Cancela, J. M., de Oliveira, I. M., \& Rodríguez-Fuentes, G. (2014). Effects of pilates method in physical fitness on older adults. A systematic review. European Review of Aging and Physical Activity, 11(2), 81-94.

Da Cruz, T. M. F., Germano, M. D., Crisp, A. H., Sindorf, M. A. G., Verlengia, R., da Mota, G. R., Lopes, C. R. (2014). Does pilates training change physical fitness in young basketball athletes? Journal of Exercise Physiologyonline, 17(1), 1-9.

Emery, K., De Serres, S.J, McMillan, A., Cote, J.N. (2010). The effects of a pilates training program on arm-trunk posture and movement. Clin Bio Mechanics, 25(2), 124-130.

Jago, R., Jonker, M.L., Missaghian, M., Baranowski, T. (2006). Effect of 4 weeks of pilates on the body composition of young girls. Preventive Medicine, 42(3), 177-180.

Miles, M, B., \& Huberman, A. M. (1994). Qualitative data analysis: An expanded Sourcebook. (2nd ed). Thousand Oaks, CA: Sage. 
Mamashli, S., Mahdavinejad, R., Gholamali, G. (2014). The effect of eight weeks pilates and stabilization exercises on pain and flexibility of back muscles and hamstring of women with chronic low back pain. Assian Journal of Multidisciplinary Studies, 2(2), 54-58.

Pourvaghar, M. J., Bahram, M. E., Sharif, M. R., Sayyah, M. (2014). Effects of eight weeks of pilates exercise on general health condition of aged male adults. International Journal of Sport Studies, 4(8), 895-900.

Rogers, K., Gibson, A.L. (2009). Eight week traditional mat pilates training-program effects on adult fitness characteristics. Res Q ExercSport, 80(3), 569-574.

Singh, T. N., Singh, S. V. K. (2014). Effect of twelve weeks exercise program with pilates on body composition among school boys of manipur. International Educational E-Journal, 3(1), 214-220.

Selby, A. (2002). Pilates For Pregnancy. London. Harper Collins Publishers Ltd.

Tsai, Y. W., Liou, T. H., Kao, Y. H., Wang, K. M., Huang, Y. C. (2013). Effect of a 12-week pilates course on body composition and cardiopulmonary fitness of adults living in an urban community. South African Journal for Research in Sport Physical Education and Recreation, 35(2), 183-195.

Yıldırım, A.; Şimşek, H. (2016). Sosyal bilimlerde nitel araştırma yöntemleri. Ankara: Seçkin Yayınc1lik. 